\title{
Sirtuins in Aging and Disease
}

\author{
L. GuARENTE \\ Department of Biology, Massachusetts Institute of Technology, Cambridge, Massachusetts 02139
}

\begin{abstract}
Sirtuin genes function as anti-aging genes in yeast, Caenorhabditis elegans, and Drosophila. The NAD requirement for sirtuin function indicates a link between aging and metabolism, and a boost in sirtuin activity may in part explain how calorie restriction extends life span. In mammals, one of the substrates of the SIR2 ortholog, SIRT1, is a regulator of mitochondrial biogenesis, PGC-1 $\alpha$. Indeed, the putative SIRT1 activator resveratrol has been shown to stimulate mitochondrial biogenesis and deliver health benefits in treated mice. I explore here how mitochondrial biogenesis may have beneficial effects on aging and, perhaps, diseases of aging. In particular, I speculate that SIRT1-mediated mitochondrial biogenesis may reduce the production of reactive oxygen species, a possible cause of aging, and offer two possible mechanisms for this effect. An understanding of how calorie restriction works may lead to novel drugs to combat diseases of aging.
\end{abstract}

\section{INTRODUCTION}

Studies on aging in model systems have revealed a class of proteins termed sirtuins (homologs of yeast Sir2) that counteract aging (Blander and Guarente 2004). The founding member, yeast SIR2, extends the life span of mother cells by suppressing the formation of toxic rDNA circles (Sinclair and Guarente 1997) and by other mechanisms including management of oxidatively damaged molecules (Aguilaniu et al. 2003). The activity of SIR2 is increased by moderate calorie restriction (CR) and the SIR2 gene is essential for the observed extension in life span by CR in many yeast strains (Lin et al. 2000, 2002; Anderson et al. 2003). In some yeast strains, Sir2 paralogs HST1 and HST2 also have a role in life extension by CR (Lamming et al. 2005).

The generality of sirtuins as anti-aging genes was shown by the life-extending effects of overexpression of SIR2 orthologs in C. elegans (Tissenbaum and Guarente 2001) and Drosophila (Rogina and Helfand 2004). Why are sirtuins pervasive regulators of aging in nature? An important clue was provided by the discovery that SIR2 and the human ortholog SIRT1 possess a unique biochemical activity-NAD-dependent protein deacetylase (Imai et al. 2000; Landry et al. 2000). This suggested that sirtuins are agents that regulate life span in accord with metabolism, which is in turn dictated by diet. The enzymatic activity of sirtuins is what actually prompted an examination of their possible role in CR. It now seems that that this role is quite general, because mammalian sirtuins, SIRT1 and SIRT4, have been clearly linked to several physiological processes regulated by diet (see below). This chapter discusses sirtuins and CR largely from an angle not usually sufficiently considered-the role of sirtuins in mitigating aging and diseases of aging by regulating mitochondrial function. Although many studies have linked SIRT1 to metabolic and stress-resistance pathways, the role of this sirtuin in regulating mitochondrial biogenesis may be central to the salutary effects of CR.

\section{METABOLIC AND STRESS-SENSING PATHWAYS REGULATED BY SIRT1}

Although the yeast Sir2p was shown to function by deacetylating histones, a large number of SIRT1 protein substrates have been identified that are nonhistone nuclear proteins. These tend to be transcription factors and cofactors that control a number of important physiological pathways in mammals. Figure 1 shows a partial listing of these substrates and groups them into two categories. The first group consists of regulators, the deacetylation of which by SIRT1 would confer resistance to cellular stress. For example, two of the early-defined substrates of SIRT1 are p53 (Luo et al. 2001; Vaziri et al. 2001) and FOXO proteins (Brunet et al. 2004; Motta et al. 2004), which respond to stress and mediate DNA repair and apoptosis. Most interestingly, the deacetylation of both p53 and FOXO proteins reduces apoptosis, whereas FOXO deacetylation also boosts expression of targets involved in DNA repair. It is very clear that fostering cellular repair and reducing cell loss would be consistent with an anti-aging effect on the organism, particularly in tissues comprising nondividing cells. Indeed, in neurons and cardiac myocytes, SIRT1 was shown to protect cells against stress-induced damage (Araki et al. 2004; J. Chen et al. 2005; Qin et al. 2006; Alcendon et al. 2007; Kim et al. 2007). The down-regulation of $\mathrm{p} 53$ is somewhat vexing from the perspective of cancer because CR is known to suppress cancer. Thus, one is compelled to consider the possibility that other SIRT1driven anti-cancer mechanisms may exist to override any partial reduction in $\mathrm{p} 53$ activity.

The second category of proteins targeted by SIRT1 (Fig. 1) is involved in metabolism. In this group are regulators of adipocyte biology, including PPAR $\gamma$ and PGC$1 \alpha$. PPAR $\gamma$ is a nuclear receptor that drives adipogenesis in white adipose tissue. By down-regulating PPAR $\gamma$ by docking with negative cofactors (Picard et al. 2004), SIRT1 is predicted to reduce adipogenesis. PGC- $1 \alpha$ is a transcriptional coactivator that promotes mitochondrial biogenesis in the muscle and gluconeogenesis in the liver 


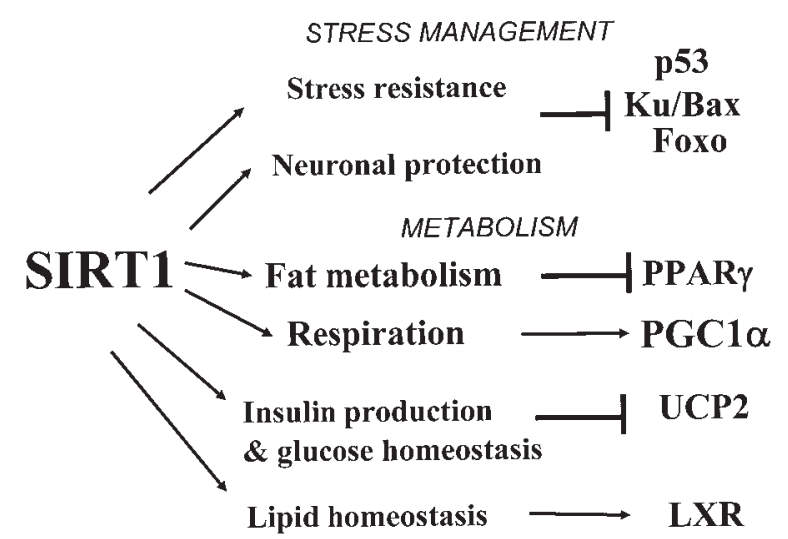

Figure 1. Targets of SIRT1 in mammalian cells. Targets known to be regulated and/or deacetylated by SIRT1 are grouped into two functional categories: stress resistance and metabolism. The p53, FOXO, and $\mathrm{Ku}$ (Cohen et al. 2004a) proteins are deacetylated by SIRT1 to reduce the tendency of cells to undergo apoptosis when exposed to damage. The deacetylation of FOXO proteins also boosts cellular capacity to repair the damage. Neuroprotection by SIRT1 overexpression and/or resveratrol treatment has been observed in vivo in mice and also in cultured neurons. On the metabolic side, SIRT1 represses PPAR $\gamma$ and deacetylates PGC- $1 \alpha$ and LXR $\alpha$ and $\beta$ to effect aspects of fat metabolism, respiration, and lipid homeostasis, as indicated. Regulation of insulin secretion in $\beta$ cells occurs by repression of UCP2 and regulates glucose homeostasis. SIRT1 has also been shown to confer stress resistance to these cells by deacetylating FOXO1 (Kitamura et al. 2005).

(Lin et al. 2005). By deacetylating PGC-1 $\alpha$, SIRT1 has been shown to up-regulate its activity, thus potentiating increases in PGC- $1 \alpha$-dependent processes in cells (Rodgers et al. 2005; Gerhart-Hines et al. 2007). Note that most of these metabolic effects described above would sensitize the animal to insulin action and thus promote efficient metabolism of glucose.

In the $\beta$ cells of the pancreas, SIRT1 has been shown to be a positive regulator of insulin secretion by repressing the mitochondrial uncoupling protein UCP2 (Moynihan et al. 2005; Bordone et al. 2006). Again, this effect would place SIRT1 on the side of efficient glucose clearance from blood. Another target of SIRT1 may be NF- $\kappa B$, the deacetylation of which was reported to repress its activity (Yeung et al. 2004). Perhaps in this case, one functional role is to reduce the proinflammatory activity of macrophages driven by NF- $\mathrm{BB}$, which again would be consistent with life extension. However, a complication of this latter mechanism may be a down-regulation of the innate immune response, and it should be fascinating to see more generally how sirtuins influence the immune system.

\section{A CONSERVED CR PATHWAY THAT INCREASES MITOCHONDRIA}

CR studies in yeast have been plagued by confusion sown by the use of different degrees of glucose deprivation. In the method employed by the labs of Guarente, Sinclair, and Lin, glucose is reduced from the canonical $2 \%$ to $0.5 \%$, a regimen I will call moderate CR (Lin et al. 2000, 2002; Anderson et al. 2003; Easlon et al. 2007). The method used by the Kaeberlein/Kennedy labs used $0.05 \%$ glucose, which I will call severe CR (Kaeberlein et al. 2004, 2005b). Although the longevity engendered by moderate CR generally was shown to require SIR2, that of severe CR was not. A recent paper from Easlon et al. (2007) clarified the distinction between these protocols. Employing the yeast strain used by Kennedy, these authors showed in a single controlled experiment that the longevity engendered by moderate $\mathrm{CR}$ required sirtuin genes, whereas that induced by severe CR did not (Fig. 2). In the latter case, life extension was actually repressed by sirtuins, suggesting that severe CR may invoke novel pathways that are actually interfered with by sirtuins.

The question arises whether moderate or severe CR in yeast is a better model of CR in higher organisms. Another important distinction between the two yeast mechanisms is that moderate CR induced a boost in mitochondrial respiration, which was required for life span extension; deletion of CYT1 encoding cytochrome $c_{1}$ abolished the SIR2-dependent extension in life span in moderate CR (Lin et al. 2002). In contrast, severe CR did not require mitochondria at all (Kaeberlein et al. 2005a). Furthermore, triggering mitochondrial biogenesis by enforced expression of the transcription factor HAP4 gave rise to a long life span in $2 \%$ glucose that could not be further extended by moderate CR (Lin et al. 2002). This experiment shows that the boost in respiration is sufficient to extend the life span. More specifically, life span was also extended sim-

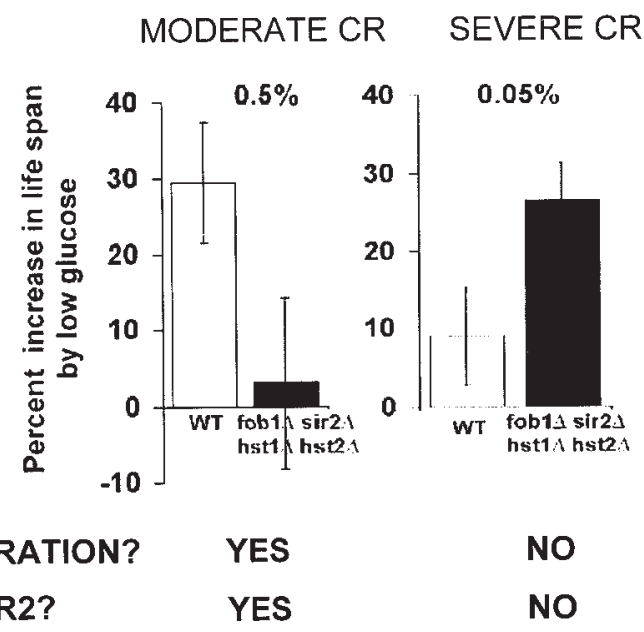

Figure 2. A requirement of $S I R 2$ genes for $\mathrm{CR}$ in yeast. This figure (Easlon et al. 2007) shows the effects of moderate CR $(0.5 \%$ glucose) and severe CR $(0.05 \%$ glucose $)$ on life span of yeast mother cells. In the wild-type strain BKY4742 (Kaeberlein et al. 2005a) both moderate and severe CR extend life span, although moderate CR extends more (open bars). (Closed bars) Strain in which three sirtuin genes (SIR2, HST1, and HST2) have been deleted as well as the $F O B 1$ gene (to prevent rDNA recombination). In this strain, moderate CR no longer extends the life span, but severe CR works even better. This study shows that sirtuins are essential for the extension of life span by moderate $\mathrm{CR}$, but they are not necessary and even antagonistic for extension of life span by severe CR. Furthermore, the figure indicates that moderate $\mathrm{CR}$ is known to require respiration for extension of the life span, whereas severe CR does not. (Reprinted, with permission, from Easlon et al. 2007 [CAmerican Society for Biochemistry and Molecular Biology].) 
ply by overexpressing the NADH dehydrogenases, NDE1 or NDI1, which donate electrons from NADH to the electron transport chain (Lin et al. 2002).

Three recent studies suggest that the induction of respiration by $\mathrm{CR}$ may be general (Fig. 3). First, CR mice (60-70\% ad libitum feeding) showed an increase in mitochondria biogenesis and a higher rate of respiration than ad libitum-fed controls (Nisoli et al. 2005). Interestingly, these increases seemed to work via induction of endothelial nitric oxide synthase (eNOS) to increase the levels of nitric oxide, which the authors showed was an inducer of SIRT1 gene expression. Second, humans on a CR diet for 6 months showed increases in expression of mitochondrial proteins in muscle, as well as SIRT1 itself (Civitarese et al. 2007). Third, C. elegans on a regimen of dietary restriction increased their respiration, and blocking this increase with respiration inhibitors prevented the extension in life span (Bishop and Guarente 2007). In this last example, the boost in respiration throughout the animal was triggered by the action of the $s k n-1$ gene transcription factor acting in just two neurons in the head of the worm. The effects on respiration and life span are evidently triggered by an endocrine-based mechanism emanating from these two cells.

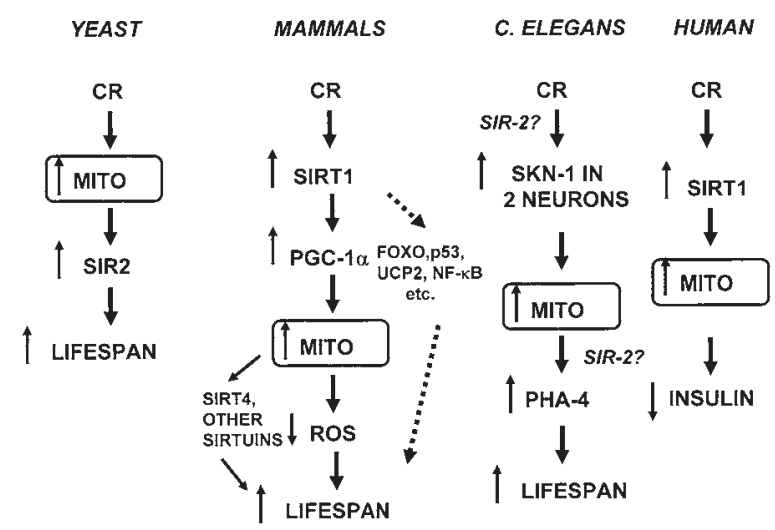

Figure 3. CR pathways across species. Shown is what is known about CR pathways in the four indicated species. In yeast, CR increases mitochondrial respiration, which activates SIR2 and extends the life span. In mammals, CR also activates SIRT1 in certain tissues (via increasing eNOS activity), which leads to deacetylation and activation of PGC-1 $\alpha$, increased mitochondrial biogenesis, and increased life span. We suggest that a key mechanism of this mammalian pathway may be a reduction in ROS by the increased mitochondrial biogenesis, as discussed in the text and Fig. 4. Effects of SIRT1 on other targets and effects of other sirtuins may also be important, as indicated. In C. elegans, CR up-regulates the SKN-1 transcription factor in the two ASI neurons in the head, which leads to a systemic increase in respiration accompanied by activation of the forkhead protein PHA-4 and an increase in life span. Possible positions where any of the four sirtuin genes could have roles in this pathway are indicated. In humans, 6-month CR was shown to lead to activation of expression of SIRT1 and mitochondrial proteins in muscle, as determined by analysis of punch biopsies. Physiological changes observed in rodents, such as reduction in blood insulin, are also observed in these people. For all four organisms, the increase in mitochondria is boxed to emphasize its position in the pathway relative to SIR2 orthologs; i.e., in yeast, SIR2 lies downstream from mitochondria, and in mammals, the ortholog SIRT1 lies upstream.
Upon inspection, there appears to be a major difference in the relationship between sir2 genes and mitochondria in CR pathways of different organisms (Fig. 3). In yeast, SIR2 lies downstream from mitochondria. This makes sense in light of the finding that the increase in respiration increases the NAD/NADH ratio, which is one of the mechanisms that can activate the SIR2 enzyme to extend life span (Lin et al. 2004). Another mechanism of SIR2 activation during $\mathrm{CR}$ is an increase in the expression of $\mathrm{PNC1}$, an NAD salvage synthesis enzyme, which consumes the known SIR2 inhibitor, nicotinamide (Anderson et al. 2003). In mice, however, SIRT1 lies upstream of mitochondria. SIRT1 protein levels in muscle are induced by CR (Cohen et al. 2004b). As discussed above, one of the important substrates for SIRT1 is the transcriptional coactivator, PGC- $1 \alpha$, which is an inducer of mitochondrial biogenesis (Rodgers et al. 2005). By deacetylating PGC- $1 \alpha$ and thereby increasing its activity, SIRT1 promotes the biogenesis of mitochondria, a topic expanded upon below. Although SIRT1 was shown to be required for at least one output of CR in mice (D. Chen et al. 2005), functional roles of sirtuins in $\mathrm{CR}$ in C. elegans and humans have not been shown as of this time.

The increase in SIRT1 activity in CR is also expected to affect other targets in mammalian cells. For example, deacetylation of SIRT1 described above like FOXO proteins and p53 may promote stress resistance during CR. However, the increase in PGC- $1 \alpha$ and the resulting mitochondrial biogenesis may be the major driving force for the health benefits of $\mathrm{CR}$ and is the subject explored below.

The fact that SIRT1 functions upstream of mitochondrial biogenesis in mice does not preclude the possibility that sirtuins may also function downstream from (i.e., in response to) the increase. For example, the mitochondrial ADP-ribosyl-transferase SIRT4 is known to be down-regulated by $\mathrm{CR}$, and it has been suggested that changes in the NAD/NADH ratio concomitant with changes in respiration rates may mediate this effect (Haigis et al. 2006). The down-regulation of SIRT4 during CR leads to an increase in the activity of its substrate for ADP-ribosylation, the crucial mitochondrial enzyme, glutamate dehydrogenase, which facilitates the entry of glutamine and glutamate into central metabolism. The use of amino acids as carbon and energy sources may be particularly important during CR. This logic may also apply to the other mitochondrial sirtuins, SIRT3 and SIRT5. A final point is that even SIRT1 itself may also function downstream from the mitochondrial respiration change, although this has not yet been shown.

\section{HOW MIGHT MITOCHONDRIAL BIOGENESIS PROTECT AGAINST DAMAGE?}

As mentioned above, it is possible that the function of sirtuins or other proteins can be regulated by respiration, and these downstream effects may mediate the benefits of $\mathrm{CR}$. Another intriguing possibility is that mitochondrial biogenesis is salutary per se. Why might this be? One simple possibility is that mitochondria are subject to damage over time by toxic by-products of respiration, reactive 
oxygen species (ROS). ROS have long been proposed as a causative agent in aging because they damage proteins, DNA, and lipids in cells, and their effects are cumulative (Harmon 1956). Having more mitochondria might buffer over the progressive loss of these ATP-generating organelles over time and mitigate deleterious effects on diseases of aging (Wallace 2005).

Another more subtle possibility is that mitochondrial biogenesis reduces the production of ROS. Figure 4 shows possible mechanisms how SIRT1/PGC- $1 \alpha$-driven biogenesis of mitochondria may reduce ROS. A common misconception is that an increase in respiration would necessarily trigger an increase in production of ROS. In fact, ROS are produced when electrons are stalled on complexes I and III of the electron transport chain and combine with local oxygen to produce ROS (Barros et al. 2004; Barja 2007).

By this reckoning, there are at least two possible ways that increased mitochondria biogenesis may reduce ROS. First, electrons can stall when the charge gradient across the mitochondrial membrane generated by proton extrusion becomes too steep, for example, under conditions of excess energy and high levels of NADH (Fig. 4). It simply becomes more difficult for the electron transport chain to pump more protons out of mitochondria against this hyperpolarized gradient. An expanded mitochondrial surface would reduce the steepness of the charge gradient by spreading the charges over a larger area and, in this

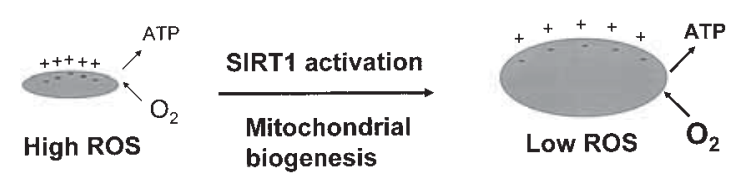

\begin{tabular}{|c|c|c|}
\hline $\begin{array}{l}\text { Small mito area } \\
\text { Steep proton gradient } \\
\text { ET stalls at complex I \& III } \\
\stackrel{\longrightarrow}{\longrightarrow} \mathrm{e}^{-}+\mathrm{O}_{2}=\mathrm{ROS}\end{array}$ & Model 1 & $\begin{array}{l}\text { Expanded Mito area } \\
\text { Relaxed gradient } \\
\text { ET flows } \\
\text { Low ROS }\end{array}$ \\
\hline $\begin{array}{l}\text { Low respiration } \\
\text { High local } \mathrm{O}_{2} \\
\text { More substrate for ROS } \\
\text { at complex I and III }\end{array}$ & Model 2 & $\begin{array}{l}\text { High respiration } \\
\text { Low local } \mathrm{O}_{2} \\
\text { Less substrate for ROS } \\
\text { at complex I and III }\end{array}$ \\
\hline
\end{tabular}

Figure 4. Relationship between mitochondrial biogenesis and ROS production. It is known that CR increases mitochondrial biogenesis and reduces the production of ROS. This figure suggests two possible mechanisms for a causal relationship between mitochondrial biogenesis and reduced ROS. In model 1, the increase in biogenesis is proposed to spread the charge gradient generated by proton pumping across the mitochondrial membrane over a larger surface area, thereby reducing the steepness of the charge gradient across the membrane. This reduction will ameliorate the stalling of electrons in the electron transport chain. This stalling is known to cause the production of ROS by complexes I and III of that chain because stalled electrons can leech off, combine with $\mathrm{O}_{2}$, and form ROS. In model 2, the increase in mitochondrial biogenesis is proposed to increase respiration, thereby lowering local $\mathrm{O}_{2}$ levels available for the production of ROS by complexes I and III. Because the components of the chain that use $\mathrm{O}_{2}$ as a true substrate (complexes IV and V) should have a much higher affinity for $\mathrm{O}_{2}$ than complexes I and III, a partial reduction in $\mathrm{O}_{2}$ levels may reduce ROS production without compromising electron transport and respiration itself. way, may prevent electron stalling and ROS production.

A second possible mechanism (Fig. 4) is that an increase in respiration might reduce local oxygen levels and thus reduce the generation of ROS by complexes I and III (Barja 2007). In this regard, the binding of oxygen to these complexes is likely to be much less avid than the bona fide $\mathrm{O}_{2}$ using components of the chain, complex IV (cytochrome $c$ oxidase), and complex V (ATPase), so a mild reduction in oxygen levels may selectively disfavor ROS production but not impact on respiration itself.

It remains to be seen how valid these ideas are. In the first place, the extent to which ROS themselves contribute to aging and diseases of aging is not yet clear. Second, we do not know for certain that mitochondrial biogenesis would be sufficient to reduce ROS production. What we do know is that $\mathrm{CR}$ reduces the production of ROS (Weindruch and Walford 1988) and, as described above, increases mitochondrial production. Investigating whether an increase in mitochondrial biogenesis per se is what causes reduced ROS during CR is a worthy goal for future research.

\section{COULD SIRTUIN-DRIVEN MECHANISMS MITIGATE EFFECTS OF DIETARY EXCESS?}

The metabolic and mitochondrial effects discussed above are very relevant to an enlarging health problem in the developed world-metabolic syndrome induced by overeating and a sedentary lifestyle (for review, see Guarente 2006). This syndrome is characterized by glucose intolerance and obesity and is associated with cardiovascular disease and a predisposition to diabetes. If SIRT1 mediates some of the effects of CR, could manipulating its activity pharmacologically provide health benefits broadly and particularly for people with metabolic syndrome?

First, one must worry that salutary effects of CR observed in rodents might not translate to primates. In fact, current primate studies show that many of the favorable metabolic changes induced by this diet in rodents also occur in monkeys, for example, high glucose tolerance (Mattison et al. 2007). Indeed, patients in the 6month study of humans on a CR diet mentioned above showed improvements in glucose and fat homeostasis (Civitarese et al. 2007).

Several years ago, a high-throughput screen for SIRT1 activators identified several polyphenols, a class of stressinduced natural products made by plants (Howitz et al. 2003). One of these, resveratrol, is found in red wine. Although there has been some controversy about whether and how resveratrol activates SIRT1 in vitro, there have been numerous examples of biological activities of this compound that are SIR2-dependent in vivo. These include life span extension in yeast (Howitz et al. 2003), C. elegans (Viswanathan et al. 2005), and Drosophila (Wood et al. 2004) and neuroprotection (J. Chen et al. 2005) and fat reduction (Picard et al. 2004) in higher organisms.

Interestingly, two studies showed that dosing mice with resveratrol counteracted some of the adverse consequences of a high fat/high calorie diet, including short- 
ened life span (Baur et al. 2006; Lagouge et al. 2006). One of these studies went on to show that the mice fed resveratrol underwent a considerable expansion in mitochondrial number in muscle (Lagouge et al. 2006). In the C2C12 myocyte cell line, mitochondrial biogenesis was shown to be under the control of transfected PGC- $1 \alpha$ and SIRT1. Thus, this may be an example in which the pathway of SIRT1 activation detailed above, i.e., mitochondrial biogenesis, has a clear health benefit in mammals.

If indeed polyphenols or other compounds can be proven to be at least partial CR mimetics, one might expect some of the health benefits associated with this diet to accrue. In mice, $\mathrm{CR}$ protects against many of the diseases of aging, including cancer and neurodegenerative diseases (Ingram et al. 1987; Zhu et al. 1999; Wang et al. 2005). If SIRT1 or other sirtuins mediate the effects of CR, it seems likely that small molecules that can bind to them and modulate their activity similar to CR would provide benefit. In the extreme, one can imagine a magic bullet that could forestall or treat any disease for which aging is a significant risk factor, i.e., all of the major diseases, excluding infectious disease.

\section{CONCLUSIONS}

In summary, we are on the verge of understanding CR at a detailed molecular level, which may allow the development of powerful new drugs to provide some of the health benefits of this dietary regimen. Would such a class of new drugs mean that any responsibility to maintain a healthy life style would be obviated? The answer seems likely to be no. Any CR mimetic would likely move an individual some distance along the health spectrum toward the excellent health observed under CR conditions. For example, someone already in good health would obtain even better health. However, someone with metabolic syndrome or worse, diabetes, would likely be moved the same distance up the health spectrum to a place better than before, but will end up no where near as healthy as someone who began healthy. Thus, these drugs will not create carte blanche for irresponsible living. So live clean and hang on!

\section{ACKNOWLEDGMENTS}

I thank all of the scientists who have contributed to this work over the years. My lab is supported by the National Institutes of Health and The Glenn Foundation.

\section{REFERENCES}

Aguilaniu H., Gustafsson L., Rigoulet M., and Nystrom T. 2003. Asymmetric inheritance of oxidatively damaged proteins during cytokinesis. Science 299: 1751.

Alcendon R.R., Gao S., Zhai P., Zablocki D., Holle E., Yu X., Tian B., Wagner T., Vatner S.F., and Sadoshima J. 2007. Sirt1 regulates aging and resistance to oxidative stress in the heart. Circ. Res. 100: 1512 .

Anderson R.M., Bitterman K.J., Wood J.G., Medvedik O., and Sinclair D.A. 2003. Nicotinamide and PNC1 govern lifespan extension by calorie restriction in Saccharomyces cerevisiae. Nature 423: 181.

Araki T., Sasaki Y., and Milbrandt J. 2004. Increased nuclear
NAD biosynthesis and SIRT1 activation prevent axonal degeneration. Science 305: 1010.

Barja G. 2007. Mitochondrial oxygen consumption and reactive oxygen species production are independently modulated: Implications for aging studies. Rejuvenation Res. 10: 215.

Barros M.H., Bandy B., Tahara E.B., and Kowaltowski A.J. 2004. Higher respiratory activity decreases mitochondrial reactive oxygen release and increases life span in Saccharomyces cerevisiae. J. Biol. Chem. 279: 49883.

Baur J.A., Pearson K.J., Price N.L., Jamieson H.A., Lerin C., Kalra A., Prabhu V.V., Allard J.S., Lopez-Lluch G., Lewis K., Pistell P.J., Poosala S., Becker K.G., Boss O., Gwinn D., Wang M., Ramaswamy S., Fishbein K.W., Spencer R.G., Lakatta E.G., Le Couteur D., Shaw R.J., Navas P., Puigserver P., Ingram D.K., de Cabo R., and Sinclair D.A. 2006. Resveratrol improves health and survival of mice on a highcalorie diet. Nature 444: 337.

Bishop N.A. and Guarente L. 2007. Two neurons mediate dietrestriction-induced longevity in C. elegans. Nature 447: 545.

Blander G. and Guarente L. 2004. The Sir2 family of protein deacetylases (review). Annu. Rev. Biochem. 73: 417.

Bordone L., Motta M.C., Picard F., Robinson A., Jhala U.S., Apfeld J., McDonagh T., Lemieux M., McBurney M., Szilvasi A., Easlon E.J., Lin S.J., and Guarente L. 2006. Sirt1 regulates insulin secretion by repressing UCP2 in pancreatic beta cells. PLoS Biol. 4: e31.

Brunet A., Sweeney L.B., Sturgill J.F., Chua K.F., Greer P.L., Lin Y., Tran H., Ross S.E., Mostoslavsky R., Cohen H.Y., Hu L.S., Cheng H.L., Jedrychowski M.P., Gygi S.P., Sinclair D.A., Alt F.W., and Greenberg M.E. 2004. Stress-dependent regulation of FOXO transcription factors by the SIRT1 deacetylase. Science 303: 2011.

Chen J., Zhou Y., Mueller-Steiner S., Chen L.F., Kwon H., Yi S., Mucke L., and Gan L. 2005. SIRT1 protects against microglia-dependent amyloid-beta toxicity through inhibiting NF-kappaB signaling. J. Biol. Chem. 280: 40364.

Chen D., Steele A.D., Lindquist S., and Guarente L. 2005. Increase in activity during calorie restriction requires Sirt1. Science 310: 1641 .

Civitarese A.E., Carling S., Heilbronn L.K., Hulver M.H., Ukropcova B., Deutsch W.A., Smith S.R., and Ravussin E. 2007. Calorie restriction increases muscle mitochondrial biogenesis in healthy humans. PLoS Med. 4: e76.

Cohen H.Y., Lavu S., Bitterman K.J., Hekking B., Imahiverobo T.A., Miller C., Frye R., Ploegh H., Kessler B.M, and Sinclair D.A. 2004a. Acetylation of the C terminus of Ku70 by CBP and PCAF controls Bax-mediated apoptosis. Mol. Cell 13: 627.

Cohen H.Y., Miller C., Bitterman K.J., Wall N.R., Hekking B., Kessler B., Howitz K.T., Gorospe M., de Cabo R., and Sinclair D.A. 2004b. Calorie restriction promotes mammalian cell survival by inducing the SIRT1 deacetylase. Science 305: 390.

Easlon E., Tsang F., Dilova I., Wang C., Lu S.P., Skinner C., and Lin S.J. 2007. The dihydrolipoamide acetyltransferase is a novel metabolic longevity factor and is required for calorie restriction-mediated life span extension. J. Biol. Chem. 282: 6161.

Gerhart-Hines Z., Rodgers J.T., Bare O., Lerin C., Kim S.H., Mostoslavsky R., Alt F.W., Wu Z., and Puigserver P. 2007. Metabolic control of muscle mitochondrial function and fatty acid oxidation through SIRT1/PGC-1alpha. EMBO J. 26: 1913.

Guarente L. 2006. Sirtuins as potential targets for metabolic syndrome. Nature 444: 868.

Harman D. 1956. Aging: A theory based on free radical and radiation chemistry. J. Gerontol. 11: 298.

Haigis M.C., Mostoslavsky R., Haigis K.M., Fahie K., Christodoulou D.C., Murphy A.J., Valenzuela D.M., Yancopoulos G.D., Karow M., Blander G., Wolberger C., Prolla T.A., Weindruch R., Alt F.W., and Guarente L. 2006. SIRT4 inhibits glutamate dehydrogenase and opposes the effects of calorie restriction in pancreatic beta cells. Cell 126: 941. 
Howitz K.T., Bitterman K.J., Cohen H.Y., Lamming D.W., Lavu S., Wood J.G., Zipkin R.E., Chung P., Kisielewski A., Zhang L.L., Scherer B., and Sinclair D.A. 2003. Small molecule activators of sirtuins extend Saccharomyces cerevisiae lifespan. Nature 425: 191.

Imai S., Armstrong C.M., Kaeberlein M., and Guarente L. 2000. Transcriptional silencing and longevity protein Sir2 is an NAD-dependent histone deacetylase. Nature 403: 795.

Ingram D.K., Weindruch R., Spangler E.L., Freeman J.R., and Walford R.L. 1987. Dietary restriction benefits learning and motor performance of aged mice.

J. Gerontol. 42: 78.

Kaeberlein M., Kirkland K.T., Fields S., and Kennedy B.K. 2004. Sir2-independent life span extension by calorie restriction in yeast. PLoS Biol. 2: E296.

Kaeberlein M., Hu D., Kerr E.O., Tsuchiya M., Westman E.A., Dang N., Fields S., and Kennedy B.K. 2005a. Increased life span due to calorie restriction in respiratory-deficient yeast. PLoS Genet. 1: e69.

Kaeberlein M., Powers R.W.,III, Steffen K.K., Westman E.A., Hu D., Dang N., Kerr E.O., Kirkland K.T., Fields S., and Kennedy B.K. 2005b. Regulation of yeast replicative life span by TOR and Sch9 in response to nutrients. Science 310: 1193.

Kim D., Nguyen M.D., Dobbin M.M., Fischer A., Sananbenesi F., Rodgers J.T., Delalle I., Baur J.A., Sui G., Armour S.M., Puigserver P., Sinclair D.A., and Tsai L.H. 2007. SIRT1 deacetylase protects against neurodegeneration in models for Alzheimer's disease and amyotrophic lateral sclerosis. EMBO J. 26: 3169 .

Kitamura Y.I., Kitamura T., Kruse J.P., Raum J.C., Stein R., Gu W., and Accili D. 2005. FoxO1 protects against pancreatic beta cell failure through NeuroD and MafA induction. Cell Metab. 2: 153.

Lagouge M., Argmann C., Gerhart-Hines Z., Meziane H., Lerin C., Daussin F., Messadeq N., Milne J., Lambert P., Elliott P., Geny B., Laakso M., Puigserver P., and Auwerx J. 2006. Resveratrol improves mitochondrial function and protects against metabolic disease by activating SIRT1 and PGC1alpha. Cell 127: 1109.

Lamming D.W., Latorre-Esteves M., Medvedik O., Wong S.N., Tsang F.A., Wang C., Lin S.J., and Sinclair D.A. 2005. HST2 mediates SIR2-independent life-span extension by calorie restriction. Science 309: 1861.

Landry J., Sutton A., Tafrov S.T., Heller R.C., Stebbins J., Pillus L., and Sternglanz R. 2000. The silencing protein SIR2 and its homologs are NAD-dependent protein deacetylases. Proc. Natl. Acad. Sci. 97: 5807.

Lin S.J., Defossez P.A., and Guarente L. 2000. Requirement of NAD and Sir2 for life-span extension by calorie restriction in Saccharomyces cerevisiae. Science 289: 2126.

Lin S.J., Ford E., Haigis M., Liszt G., and Guarente L. 2004. Calorie restriction extends yeast lifespan by lowering the level of NADH. Genes Dev. 18: 12 .

Lin S.J., Kaeberlein M., Andalis A.A., Sturtz L.A., Defossez P.A., Culotta V.C., Fink G.R., and Guarente L. 2002. Calorie restriction extends Saccharomyces cerevisiae lifespan by increasing respiration. Nature 418: 344.

Lin J., Handschin C., and Spiegelman B.M. 2005. Metabolic control through the PGC-1 family of transcription coactivators (review). Cell Metab. 1: 361.

Luo J., Nikolaev A.Y., Imai S., Chen D., Shiloh A., Guarente L., and $\mathrm{Gu}$ W. 2001. Negative control of p53 by Sir2a promotes cell survival under stress. Cell 107: 137.

Mattison J.A., Roth G.S., Lane M.A., and Ingram D.K. 2007. Dietary restriction in aging nonhuman primates. Interdiscip. Top. Gerontol. 35: 137.
Motta M.C., Divecha N., Lemieux M., Kamel C., Chen D., Gu W., Bultsma Y., McBurney M., and Guarente L. 2004. Mammalian SIRT1 represses forkhead transcription factors. Cell 116: 551 .

Moynihan K.A., Grimm A.A., Plueger M.M., Bernal-Mizrachi E., Ford E., Cras-Meneur C., Permutt M.A., and Imai S. 2005 Increased dosage of mammalian Sir2 in pancreatic beta cells enhances glucose-stimulated insulin secretion in mice. Cell Metab. 2: 105 .

Nisoli E., Tonello C., Cardile A., Cozzi V., Bracale R., Tedesco L., Falcone S., Valerio A., Cantoni O., Clementi E., Moncada S., and Carruba M.O. 2005. Calorie restriction promotes mitochondrial biogenesis by inducing the expression of eNOS. Science 310: 314.

Picard F., Kurtev M., Chung N., Topark-Ngarm A., Senawong T., Machado De Oliveira R., Leid M., McBurney M.W., and Guarente L. 2004. Sirt1 promotes fat mobilization in white adipocytes by repressing PPAR-gamma. Nature 429: 771.

Qin W., Yang T., Ho L., Zhao Z., Wang J., Chen L., Zhao W., Thiyagarajan M., MacGrogan D., Rodgers J.T., Puigserver P., Sadoshima J., Deng H., Pedrini S., Gandy S., Sauve A.A., and Pasinetti GM. 2006. Neuronal SIRT1 activation as a novel mechanism underlying the prevention of Alzheimer disease amyloid neuropathology by calorie restriction. J. Biol. Chem. 281: 21745.

Rogina B. and Helfand S.L. 2004. Sir2 mediates longevity in the fly through a pathway related to calorie restriction. Proc. Natl. Acad. Sci. 101: 15998.

Rodgers J.T., Lerin C., Haas W., Gygi S.P., Spiegelman B.M., and Puigserver P. 2005. Nutrient control of glucose homeostasis through a complex of PGC-1alpha and SIRT1. Nature 434: 113 .

Sinclair D.A. and Guarente L. 1997. Extrachromosomal rDNA circles: A cause of aging in yeast. Cell 91: 1033 .

Tissenbaum H.A. and Guarente L. 2001. Increased dosage of a sir-2 gene extends lifespan in Caenorhabditis elegans. Nature 410: 227.

Vaziri H., Dessain S.K., Ng Eaton E., Imai S.I., Frye R.A., Pandita T.K., Guarente L., and Weinberg R.A. 2001. hSIR2(SIRT1) functions as an NAD-dependent p53 deacetylase. Cell 107: 149.

Viswanathan M., Kim S.K., Berdichevsky A., and Guarente L. 2005. A role for SIR-2.1 regulation of ER stress response genes in determining C. elegans life span. Dev. Cell 9: 605.

Wallace D.C. 2005. A mitochondrial paradigm of metabolic and degenerative diseases, aging, and cancer: A dawn for evolutionary medicine (review). Annu. Rev. Genet. 39: 359.

Wang J., Ho L., Qin W., Rocher A.B., Seror I., Humala N., Maniar K., Dolios G., Wang R., Hof P.R., and Pasinetti G.M. 2005. Caloric restriction attenuates beta-amyloid neuropathology in a mouses model of Alzheimer's disease. FASEB J. 19: 659.

Weindruch R. and Walford R. L. 1988. The retardation of aging and disease by dietary restriction. C.C. Thomas, Springfield, Illinois.

Wood J.G., Rogina B., Lavu S., Howitz K., Helfand S.L., Tatar M., and Sinclair D. 2004. Sirtuin activators mimic caloric restriction and delay ageing in metazoans. Nature 430: 686.

Yeung F., Hoberg J.E., Ramsey C.S., Keller M.D., Jones D.R., Frye R.A., and Mayo M.W. 2004. Modulation of NF-kappaBdependent transcription and cell survival by the SIRT1 deacetylase. EMBO J. 23: 2369.

Zhu H., Guo Q., and Mattson M.P. 1999. Dietary restriction protects hippocampal neurons against the death-promoting action of a presenilin-1 mutation. Brain Res. 842: 224. 


\section{$8_{\mathrm{CSH}}^{\infty} \mathrm{C}$ Cold Spring Harbor Symposia SYMPOSIA}

\section{Sirtuins in Aging and Disease}

L. Guarente

Cold Spring Harb Symp Quant Biol 2007 72: 483-488

Access the most recent version at doi:10.1101/sqb.2007.72.024

References This article cites 54 articles, 18 of which can be accessed free at: http://symposium.cshlp.org/content/72/483.full.html\#ref-list-1

\section{License}

Email Alerting

Receive free email alerts when new articles cite this article - sign up in the box at the Service top right corner of the article or click here.

To subscribe to Cold Spring Harbor Symposia on Quantitative Biology go to: http://symposium.cshlp.org/subscriptions 